\title{
KIERKEGAARD Y LA PSICOLOGÍA EXISTENCIAL
}

\author{
Gabriel de Reina Tartière \\ Universidad de Oviedo, España
}

\section{Resumen}

Pese al enfoque dado por Kierkegaard a gran parte de su obra, de marcado carácter psicológico, y la influencia que ha tenido en las distintas escuelas actuales en materia de psicoterapia, resulta necesario poner en orden algunas ideas básicas sobre el exacto alcance de esa influencia, mucho mayor de lo que demuestran los pocos estudios específicos que existen sobre el tema. El presente trabajo tratará de dar un bosquejo general, pero técnico, a las cuestiones trascendentales que hicieran nacer en el seno de la denominada "Tercera Fuerza" de la Psicología, la corriente existencial, sin obviar los aspectos distintivos respecto de su contenido.

Palabras clave: Psicología, psicoterapia, existencialismo, angustia, desesperanza.

\section{Abstract}

Despite the approach given by Kierkegaard to a large part of his work, which has a marked psychological character, and the influence it has had in the different schools of psychotherapy, it is necessary to put in order some basic ideas about the exact scope of that influence, much greater than what the few specific studies that exist on the subject show. The present work will try to give a general, but technical, outline of the transcendental issues that would arise within the so-called "Third Force" of Psychology, the existential current, without ignoring the distinctive aspects regarding its content.

Key words: Psychology, psychotherapy, existentialism, anxiety, despair.

\section{Introducción}

"La psiquiatría (rama de la medicina que trata la enfermedad mental) carece de sentido. Y la psicología, por su parte, no es, y nunca será, una 'ciencia empírica'. No se puede pesar ni medir la 'mente'. La psiquiatría

Recibido: 9 de febrero de 2018; Aceptado: 22 de marzo de 2018. 
es una mentira y la psicología no sabe lo que es. La una está psicótica y la otra neurótica perdida”. Así se presenta por Rafael Millán su reciente libro Las enfermedades mentales no existen...son los padres ${ }^{1}$, siguiendo la estela ya consolidada de la antipsiquiatría, y sobre todo recordando el best seller de Szasz sobre el mito de la patología mental de $1961^{2}$. Desde esta perspectiva, la enfermedad mental, ilocalizable en un punto concreto neurológico por donde intervenir, como ocurre con cualquier otra enfermedad normal (por cuanto traumática, física o hasta fisiológica) no remitiría más que a la existencia de los problemas vitales que persiguen al hombre durante su devenir, por lo que la enfermedad sería un mero constructo, un mito, en suma, que ni siquiera justificaría desde la radicalidad de tal posición la psicoterapia como remedio por la vía del talking cure.

Pero el envión antipsiquiátrico, no obstante su persistencia, poco tiene que ver con la psicología cuando se refiere a ésta, entre otras cosas, porque avanzando tanto sobre ella pretende negarla, y esa pretensión de negación es su perdición, por ambiciosa. Podrá mantenerse una u otra noción acerca de la enfermedad mental y propender al cierre de los psiquiátricos como centros de marginación social como logró Franco Basaglia junto a su equipo y movimiento en Italia donde llegara a hacerse por ley, la ley 180, de 1978; pero los problemas existen, se tengan o llamen como quieran, y porque existen esos problemas, y muy marcadamente, en nuestra época -la angustia, la desesperación, el vacío o neurosis existencial, la insatisfacción general etc.-, el manicomio puede haberse impugnado como recinto, como espacio material, pero no como cuadro general del paciente, del sufriente, si se prefiere, al que un tratamiento profesional hay que dar. Decir, así, que la psicología, cualidad, antes de nada, que viene con el hombre, ha perdido su sentido se antoja desconocer que la mente es un conjunto de funciones entre las que late primordialmente la conciencia, pero que nada tiene que ver con el órgano donde se producen, el cerebro. Por eso, el nuevo salto a una suerte de "contrapsicología", cuando no habría todavía convencido, ni convencerá, el anterior relativo a la antipsiquiatría, no sería más que un salto al vacío, por motivo de una general abstención ideologizada e ideologizante. Que el paradigma científico stricto sensu no pueda aplicarse a la psicología es consecuencia de la compleja naturaleza del hombre, y

${ }^{1}$ Rafael Millán, Las enfermedades mentales no existen...son los padres, Madrid: Manuscritos, 2017.

${ }^{2}$ Exactamente: Thomas Szasz, The Myth of Mental Illness: Foundations of a Theory of Personal Conduct, Nueva York: Hoeber \& Row, 1961. 
de lo que se ha llamado "crisis permanente de la psicología", que no debe asustarnos habida cuenta de que con ello se refiere la pugna de corrientes en procura de una mejora constatable de sus resultados. Y esto ocurre en cualquier rama del conocimiento, y más si pertenece al elenco de las más puras ciencias humanas. Así, en el ámbito jurídico, no existe aún legislación positiva que eluda la confrontación, su interpretación conforme a las razones del Derecho natural, por ejemplo.

Por eso, pretender poner en jaquela psicología sigue siendo consecuencia de una visión cerrada de cómo se han ido sucediendo las distintas corrientes en su seno; pasando una vez todas ellas sobre el tapete, el juego ha pasado a la combinación de los distintos entramados o al descarte directo de lo demostrado ineficaz, dilatorio o, cuando menos, mejorable, y en ambos casos, desde la óptica de cada profesional habida cuenta la condición personalísima que presenta la opción del psicólogo, del psicoterapeuta para con sus pacientes. Ya que no es el paciente el que escoge directamente un modelo, que suele, en la inmensa mayoría de ocasiones, desconocer de amalgamas y tendencias y a quien no le llega ni le interesa de suyo el debate, algo que además sumaría a sus problemas un total desconcierto. Lo que el paciente ha de estar es "cómodo" en cada sesión y lograr ver su avance; esos son sus criterios básicos.

\section{La tercera fuerza en psicología: la psicología bumanista}

Antes se aludía al Derecho, en la antítesis iuspositivismo-iusnaturalismo como ejemplo de que las disciplinas no convergen hacia la uniformidad, y ello que el principio de seguridad jurídica es en tal ámbito de orden constitutivo, hoy modernamente constitucional. En Psicología ocurre justo algo parecido. Frente al positivismo del conductismo, o el materialismo psicoanalítico, a mediados del siglo pasado pronto surgió una corriente psicológica superadora del mecanismo E-R (estímulo-respuesta) o de la tópica inflexible freudiana. Era, y es, pues es hoy la tendencia dominante en psicología, la "Tercera Fuerza” o Psicología humanista, con amplísima aplicación en el campo clínico. En realidad, y como sus precursores, en Europa primero, Erich Fromm y Viktor Frankl, y luego en Estados Unidos, Abraham Maslow, Carl Rogers, Fritz Perls, Gordon Allport, George Kelly, Rollo May y un amplio etcétera, empezaron formándose desde las enseñanzas de Freud, lo más adecuado sería tener hoy ya por "Tercera 
Fuerza" aquella que contrasta con el conductismo (de I. Pavlov, J. Watson, B. F. Skinner, etc.), es cierto, pero también con el cognitivismo que viera la luz justo un poco más tarde, afianzándose en la décadas de los setenta, a partir del paradigma del proceso de información. El cognitivismo alumbra desde entonces, especialmente en el campo teórico-experimental de la memoria, el lenguaje, la atención y la percepción, favoreciéndose de las nuevas técnicas de exploración neurocerebrales; sin embargo, en su aspecto clínico ha tenido que sumarse a las terapias llamadas de primera generación, esto es, a las meramente conductuales, para gozar de una mejor aplicación.

Aclarado mínimamente el actual panorama, la pregunta, dado el objeto de este trabajo, resulta obvia: ¿por qué se llaman humanistas a las distintas visiones técnicas, casi una por autor, que se suman a la "Tercera Fuerza"? $\mathrm{El}$ interrogante no es menor dado el amplísimo margen que recibe hoy el término "humanismo" tanto que queda prácticamente sin contenido, en mera palabrería y componenda con unos ideales que exigen matizarse. Por otro lado, resolver la cuestión será vital en cuanto, si el mismo Sartre calificara el existencialismo de "un humanismo"”, por vía transitiva nada

3 "Se me ha reprochado el preguntar si el existencialismo era un humanismo. Se me ha dicho ha escrito usted en La náusea que los humanistas estaban equivocados, se ha burlado de cierto tipo de humanismo; ¿por qué volver otra vez a lo mismo ahora? En realidad, la palabra bumanismo tiene dos sentidos muy distintos. Por humanismo se puede entender una teoría que toma al hombre como fin y como valor superior. Hay humanismo en este sentido en Cocteau, por ejemplo, cuando en su relato La vuelta al mundo en ochenta horas un personaje dice, al sobrevolar en avión unas montañas: 'El hombre es asombroso'. Esto significa que yo, personalmente, que no he construido aviones me beneficiaré con estos inventos particulares, y que podré personalmente, como hombre, considerarme responsable y honrado por los actos particulares de algunos hombres. Esto supone que podríamos dar un valor al hombre de acuerdo con los actos más altos de ciertos hombres. Este humanismo es absurdo, porque solo el perro o el caballo podrían emitir un juicio de conjunto sobre el hombre y declarar que el hombre es asombroso, lo que ellos no se preocupan de hacer, por lo menos que yo sepa. Pero no se puede admitir que un hombre pueda formular un juicio sobre el hombre. El existencialismo lo dispensa de todo juicio de este género; el existencialista no tomará jamás al hombre como fin, porque siempre está por realizarse. Y no debemos creer que hay una humanidad a la que se pueda rendir culto, a la manera de Augusto Comte. El culto a la humanidad conduce al humanismo cerrado sobre sí, el de Comte, y, hay que decirlo, al fascismo. Es un humanismo que no queremos.

Pero hay otro sentido del humanismo que significa en el fondo esto: el hombre está continuamente fuera de sí mismo; es proyectándose y perdiéndose fuera de sí mismo como hace existir al hombre $y$, por otra parte, es persiguiendo fines trascendentales como puede existir; el hombre, siendo este rebasamiento mismo y no captando los objetos sino con relación a este rebasamiento, está en el corazón y en el centro de este rebasamiento. No hay otro universo que este universo humano, el universo de la subjetividad humana. Esta unión de la 
tendría que ver ese existencialismo con la obra de Kierkegaard ${ }^{4}$, que en modo alguno puede reducirse empleando el término de "humanista"; más bien, todo lo contrario, sin necesidad de buscar justificaciones al estilo sartriano. El problema, sin embargo, se resuelve en cuanto la noción de humanismo actuará aquí de predicado, adjetivando una Psicología que en cuanto tal va a cifrarse en los siguientes aspectos ${ }^{5}$ :

1) El hombre como tal sobrepasa la suma de sus partes. El hombre debe ser considerado como algo más que un resultado de la adición de varias partes y funciones.

2) El hombre lleva a cabo su existencia en un contexto bumano. Su naturaleza se expresa en su relación con los otros seres humanos.

3) El hombre es consciente. La conciencia forma parte esencial de su ser.

4) El hombre tiene capacidad de elección. La conciencia hace al hombre, no mero espectador, sino partícipe de sus experiencias.

5) El hombre es intencional. La intencionalidad es la base sobre la cual el hombre construye su identidad.

trascendencia, como constitutiva del hombre — no en el sentido de que Dios es trascendente, sino en el sentido de rebasamiento-, y de la subjetividad, en el sentido de que el hombre no está encerrado en sí mismo sino presente siempre en un universo humano, es lo que llamamos humanismo porque recordamos al hombre que no hay otro legislador que él mismo, y que es en el desamparo donde decidirá sobre sí mismo; y porque mostramos que no es sí mismo, sino siempre buscando fuera de sí un fin que es tal o cual liberación, tal o cual realización particular, como el hombre se realizará precisamente en cuanto a humano" (Jean-Paul Sartre, El existencialismo es un humanismo, [no indica trad.], Madrid: Edhasa, 2009, pp. 82-86).

${ }^{4} \mathrm{Y}$ es que, en esa misma senda terminológica que se ha advertido respecto del 'humanismo', "se ha abusado tanto del vocablo 'existencialismo' que, como han indicado varios autores allegados a esta tendencia, ya no significa apenas nada”, por lo que lo mejor para combatir este abuso es "limitar la aplicación del vocablo a cierta época y, dentro de ello, a ciertas corrientes o actitudes filosóficas. Desde este punto de vista el origen del existencialismo se remonta solamente a Kierkegaard, el cual lanzó por vez primera el grito de combate: 'contra la filosofía especulativa [principalmente la de Hegel], la filosofía existencial'. Con ello abogó por un 'pensar existencial' en el cual el sujeto que piensa — este hombre concreto y, como diría Unamuno ‘de carne y hueso' — se incluye a sí mismo en el pensar en vez de reflejar, o pretender reflejar, objetivamente la realidad” (José Ferrater Mora, "Existencialismo", en Diccionario de Filosofía, I, Buenos Aires: Editorial Sudamericana, 1964, p. 613).

${ }^{5}$ Francisco Tortosa Gil, Una historia de la psicología moderna, Madrid: McGraw-Hill, 1998, p. 504. 
Parecieran muy elementales los cinco postulados, pero no si se los contextualiza. Redactados para la Asociación Americana de Psicología Humanista $(\mathrm{AAHP})^{6}$, creación que tuvo exactamente lugar en 1962, las cinco afirmaciones atacaban directamente el corpus teórico-práctico tanto del psicoanálisis, basado en el juego de las fuerzas que mueven desde dentro al hombre (catexis), como del conductismo o mecanicismo E-R que desde fuera estaba llamado a condicionarlo. El hombre se rescata en su libertad total, en su destino, que le pertenece; en sus sanos anhelos, deseos y motivaciones; en la responsabilidad por sus actos, consecuencia lógica de ser libre, etc. Se huye, en suma, del predeterminismo psicológico cualquiera sea su forma. El paso, observado desde la psicoterapia, es de gigante y las posibilidades de crecimiento personal del paciente se expanden como nunca vistas. Y epistemológicamente el cambio no es menos radical: el hombre será el gran protagonista a partir de ahora, por encima de teorías inflexibles o limitantes en cuanto para su comprensión el enfoque se torna, como no puede ser de otro modo, global. Es así, pues, que se ha de entender el sustrato "humanista" de la "Tercera Fuerza", y la razón de tal su apelativo.

\section{La psicología existencial}

Omitiendo cuanto sobre Kierkegaard se dirá en el siguiente punto, la carta de naturaleza de la Psicología existencial se obtiene en el tiempo, sino a la vez, un tanto antes que, para la humanista, y con una enorme particularidad: la de manifestarse como una derivación, plenamente integrada, eso sí, dentro de ésta. Y es que en ambos movimientos una figura participó a la vez, para luego con los años hacer escuela, pero sin perder la orientación de aquellos presupuestos citados, de suyo lo suficientemente abiertos para dar lugar a las distintas corrientes de turno. Me refiero al psiquiatra y psicoterapeuta Rollo May (1909-1994).

En este sentido, repárese en que, si la Asociación para la Psicología Humanista se fundara en 1962, y un año antes su Revista, May ya había editado con Angel y Ellemberger en 1958 como hito trascendental el libro Existence: A New Dimension in Psychiatry and Psychology ${ }^{7}$, De inmediato, al año

\footnotetext{
${ }^{6}$ American Association of Humanistic Psychology, que había creado un año antes su propia revista, el Journal of Humanistic Psychology.

${ }^{7}$ Existence: A New Dimension in Psychiatry and Psychology, Nueva York: Basic Books, 1958.
} 
siguiente, y con ocasión de la Convención de la APA (American Psychological Association) de 1959, se celebraría una Conferencia sobre Psicología Existencial con la participación de lo más granado de la llamada "Tercera Fuerza"; así, aparte de May, Abraham Maslow, Carl Rogers, Gordon Allport y Herman Feifel. El texto de sus aportes fue recopilado luego en el libro Existencial Psychology de 1961 bajo la también coordinación de $\mathrm{May}^{8}$, donde empezara explicando -reiterando ideas propias volcadas en el libro anterior- el origen filosófico y las bases existenciales de la psicoterapia. La llamada general a Kierkegaard estaba hecha, pero antes debemos definir y caracterizar, como hicimos con la Psicología humanista, la Psicología existencial sirviéndonos de las palabras, obviamente, de su pionero y propulsor.

En primer lugar, y en lo que atañe a su definición, la existencial se centra en una nueva perspectiva acerca del hombre como paciente, sufriente en un mundo en permanente crisis, lo que quiere decir que es en el campo clínico, el de la terapia, donde viene a cumplir su primordial función. De ahí que se defina la psicoterapia existencial como "el movimiento que por una parte recurre al análisis científico de Freud [confirmándose así nuestro concepto modificado de "Tercera Fuerza"], y por otra integra en el cuadro de comprensión del hombre a un nivel más profundo y más amplio: el hombre como ser humano. Se basa en el presupuesto de que es posible construir una ciencia humana que no necesita desarticular al hombre ni pulverizar su humanidad para estudiarlo. Combina ciencia con ontología. Así, pues, no es exagerado decir que no tratamos simplemente de discutir un nuevo método en competencia con otros, para que lo tome o lo deje el que quiera o lo volatice en un vago paneclecticismo"; no, los problemas a los que se aboca "calan mucho más hondo en nuestra situación contemporánea" .

En cuanto a sus principios, y haciendo un esfuerzo por nuestra parte, pues May huyó de una sistematización propia por ser justamente contraria a la finalidad sustancial de este enfoque en psicoterapia, que es lo más que lo calificaba, podríamos aproximarnos del siguiente modo:

\section{a) La pregunta}

“¿Cómo podemos saber que estamos viendo al paciente en su mundo real, en ese mundo en que 'vive, se mueve y existe' y que es para él un mundo

${ }^{8}$ Existential Psychology, Nueva York: Random House, 1961.

9 Rollo May, “Orígenes y significado del movimiento existencial en psicología”, en Existencia: nueva dimensión en psiquiatría y psicología, ed. por Rollo May, Ernest Angel y Henri F. Ellenberger, trad. de Cecilio Sánchez Gil, Madrid: Gredos, 1977, p. 57. 
aparte, concreto y diferente de nuestras teorías generales de cultura?” o, dicho de otro modo: “¿podemos estar seguros de que vemos al paciente tal como verdaderamente es, de que lo conocemos en su propia realidad, o estamos simplemente proyectando sobre él nuestras propias teorías?” Y, a la inversa, "¿cómo podemos tener seguridad de que nuestro sistema, por muy bonito que sea en teoría y por muy elaborado que esté, tiene algo que ver con ese señor Pérez de carne y hueso, con su personalidad viviente, palpitante, sentado ante nosotros en nuestra sala de consulta?"10.

\section{b) Los motivos, el contenido}

La Psicología existencial se centra en las grandes cuestiones vitales del hombre: el amor, la voluntad, la libertad, la responsabilidad, la angustia, la desesperación, la falta de significación en el mundo, etc. Su prisma es personal, de tú a tú, con el paciente y nunca desde una perspectiva anclada en lo patológico. Se tratan los problemas de la vida se manifiesten o no con tal o cual nombre. Eso es irrelevante en cuanto lo que importa es el ser, la realidad palpitante, existencial del hombre, no la realidad o verdad abstracta con la que podría confrontarse ${ }^{11}$.

Pero, si aún y todo eso, quisiera verse en clave conflictual, la posición existencial haría hincapié "en un tipo diferente de conflicto básico: no se trata ya de una lucha contra las tendencias instintivas reprimidas ni contra los adultos significativos, tras la interiorización de sus figuras, sino de un conflicto que emana del enfrentamiento del individuo con los supuestos

${ }^{10}$ Ibíd., p. 19-20.

${ }^{11}$ Ibíd., p. 31. En Psicología existencial May desarrolla esta idea: "nuestra unidad fundamental de estudio en psicoterapia no es un 'problema' que el paciente aporta, como la impotencia; o una estructura, como la, pauta neurótica de sadomasoquismo, o una categoría de diagnóstico de una enfermedad, como la histeria o la fobia, y así sucesivamente; o un impulso o estructura de impulsos. Antes bien, nuestra unidad de estudio son dos-personasexistentes-en-un-mundo, mundo que en ese momento está representado por el consultorio del terapeuta. A decir verdad, el paciente lleva ahí todos sus problemas, su 'enfermedad', su pasado, y todo lo demás, simplemente porque son parte de él: pero lo que importa percibir claramente es que el único dato que posee realidad en ese momento es que el paciente crea determinado mundo en el consultorio, y que en el contexto de dicho mundo puede surgir cierta comprensión de su ser-en-su-mundo... Lo que señalamos aquí presenta consecuencias de vasto alcance, no solo porque apunta directamente a nuestra indagación y práctica en psicoterapia, sino también porque indica los lineamientos de una aproximación existencial a la ciencia" (Rollo May, "El surgimiento de la psicología existencial", en Psicología existencial, ed. por Rollo May, Gordon W. Allport, Gordon, Herman Feifel et. al., trad. de Marcelo Cherbi, Buenos Aires: Paidós, 1963, pp. 43-44). 
básicos de la existencia, supuestos que incorporan las llamadas cuatro preocupaciones esenciales, intrínsecas del hombre, como son la muerte, la libertad, el aislamiento y el sentido de la vida que ineludiblemente forman parte del ser humano en el mundo" ${ }^{12}$.

\section{c) El objetivo}

"La finalidad de la psicoterapia es hacer a la gente libre. Libre, todo lo posible, de fantasmas, ya sean síntomas psicosomáticos, como úlceras, o síntomas psicológicos, como timidez aguda. Libres, de nuevo, cuanto fuere posible, de ser maníacos del trabajo para ganar más, de vernos forzados a repetir hábitos torturantes aprendidos en la primera niñez, libres de vernos forzados a elegir perpetuamente compañeros del otro sexo que acarrean continua infelicidad y continuo tormento.

Pero más que todo esto, yo creo -enfatiza May- que la función del terapeuta había de ser el ayudar a la gente a hacerse libre para tener conciencia de sus posibilidades y para ponerlas a prueba. Un problema psicológico, he apuntado en otro lado, es como la fiebre; indica que algo va mal en la estructura de la persona y que se ha entablado una lucha por la supervivencia. Ello es, a su vez, una prueba de que otro modo de proceder es posible. Nuestro viejo modo de pensar, [ese por el] que los problemas están ahí para deshacernos de ellos lo más pronto posible, pasa por alto lo que es más importante; a saber, que los problemas son acontecimientos normales de la vida y que son básicos para el desenvolvimiento de la creatividad humana. Esto es verdadero, ya esté uno construyendo con las cosas, ya esté uno reconstruyéndose a sí mismo. Los problemas son signos externos de posibilidades internas no gastadas"13.

\section{d) Lo técnico}

En psicología y psiquiatría el término existencial "denota una actitud, una aproximación a los seres humanos, antes que una escuela o grupo especial", hasta plantearse May "si tiene sentido hablar de un psicólogo o psicoterapeuta existencial, en contraposición a otras escuelas; por cuanto — reitera — no se trata de un sistema de terapia, sino de una actitud hacia la

${ }^{12}$ Irvin D. Yalom, Psicoterapia existencial, trad. de Diorki, Barcelona: Herder, 1984, p. 19.

${ }^{13}$ Rollo May, Libertad y destino en psicoterapia, trad. de Luis Martínez Gómez, Bilbao: Desclée de Brouwer, 1988, p. 28. 
terapia; no de un conjunto de nuevas técnicas, sino de una preocupación por comprender la estructura del ser humano y su experiencia, las cuales deben subyacer en toda técnica. Por ello tiene sentido decir — siempre que no se interprete mal- que todo psicoterapeuta es existencial en la medida en que resulta un buen terapeuta, o sea, que es capaz de aprehender al paciente en su realidad y se caracteriza por el tipo de comprensión de presencia" ${ }^{14}$.

Con todo y con eso, y tras destacar una vez más la idea, May advertiría ya en Existence algunos rasgos mínimos para tener en cuenta en lo metodológico, a saber:

La técnica que resulte debe gozar de flexibilidad y elasticidad, "para poder variar de un paciente a otro y de una fase a otra en el tratamiento de un mismo paciente. Para decidir la técnica concreta que debe emplearse en cada momento particular han de tenerse en cuenta las siguientes cuestiones: ¿qué es lo que manifestará mejor la existencia de este individuo particular en este momento de su historia? ¿Qué es lo que iluminará con más claridad su seren-el-mundo? Esta flexibilidad no es nunca puramente ecléctica, sino que siempre implica una clara comprensión de los postulados sublatentes de cada método" 15 .

Debe tenerse en cuenta en todo caso que los dinamismos psicológicos (represión, resistencia) "siempre derivan su sentido de la situación existencial de la vida personal e inmediata de cada paciente" ${ }^{16}$. Así, no hay aquí lugar para la transferencia freudiana; no es que el neurótico transmita sus problemas a la relación con el terapeuta, sino que las hace ver en ella directamente pues forman parte de su mundo y de tal modo en la terapia los manifestaría.

El tercer punto "es la importancia que se concede a la presencia. Con esto queremos decir que se toma como real la relación entre el paciente y el terapeuta. Éste no es un puro reflector simbólico, sino un ser humano, vivo, que en ese momento no se interesa por sus propios problemas, sino por comprender y sentir en lo posible el ser de su paciente" ${ }^{17}$.

Si el objetivo de la psicoterapia existencial es el de liberar al paciente, en el proceso terapéutico la finalidad se cumpliría haciendo que "el paciente experimente su existencia como real. Se trata de que se dé plenamente cuenta

${ }^{14}$ Rollo May, "El surgimiento de la psicología existencial”, pp. 17-18.

15 Rollo May, "Contribuciones de la psicoterapia existencial”, en Existencia: nueva dimensión en psiquiatría y psicología, ed. por Rollo May, Ernest Angel y Henri F. Ellenberger, p. 107.

${ }^{16}$ Ibíd., pp. 107-108.

${ }^{17}$ Ibíd., p. 109. 
de ella, lo cual implica percibir sus potencialidades y capacitarse para actuar a base de ellas".

Finalmente, la quinta consecuencia o implicación que distingue la terapéutica existencialista es la importancia del compromiso. "La significación del compromiso, de la entrega, no radica solamente en que es una cosa vagamente buena o éticamente aconsejable, sino en que más bien es un prerrequisito necesario para ver la verdad. Esto implica un punto vital..., a saber, que la decisión precede al conocimiento. Normalmente hemos actuado sobre la suposición de que a medida que el paciente va teniendo más y más conocimiento e intuición sobre sí mismo, irá haciendo las decisiones apropiadas. Ésta es una verdad a medias. Generalmente se pasa por alto la segunda mitad de la verdad, a saber, que el paciente no puede permitirse el lujo de adquirir ese conocimiento e intuición hasta que esté dispuesto a decidir, tome una orientación decidida sobre su vida y adopte las resoluciones previas en marcha"18. En este plano, y esto es muy importante para hacerse responsable antes que libre, la decisión, "la actitud decisiva frente a la existencia precedería al conocimiento y la intuición y no al revés" 1 .

\section{La recepción de Kierkegaard}

Hablar de recepción cuando de Kierkegaard se trata y en relación con la Psicología existencial es quedarse muy corto, pues no resulta exageración advertir que sin él no existiría. Veamos cómo fue el descubrimiento, el desplazamiento incluso de las teorías freudianas a partir de lo que nos cuenta en primera persona Rollo May en ese su ensayo para el ya citado, por fundante y fundamental, libro Psicología existencial.

Después de tales intentos de definición deseo ser existencialista en este ensayo y referirme a mi propia experiencia como persona y como practicante de la psicoterapia psicoanalítica. Hace unos quince años, cuando escribía mi libro The Meaning of Anxiety, pasé un año y medio en cama en un sanatorio para tuberculosos. Dispuse de mucho tiempo para interpretar el significado de la ansiedad, y de datos de primera mano harto suficientes, tanto míos como de otros internados. Durante ese lapso estudié los únicos dos libros sobre la ansiedad publicados hasta el presente: El problema de la angustia de Freud, y El concepto de la angustia de Kierkegaard. Valoré las formulaciones de Freud: a saber, su primera teoría, según la cual la ansiedad es el resurgimiento

\footnotetext{
${ }^{18}$ Ibíd., pp. 117-118.

${ }^{19}$ Ibíd., p. 118.
} 
de la libido reprimida, y la segunda, que la ansiedad es la reacción del yo ante la amenaza de la pérdida del objeto amado. Kierkegaard, por su parte, describió la ansiedad como la lucha del ser viviente contra el no-ser, que allí pude experimentar en forma inmediata, en mi lucha contra la muerte, o ante la perspectiva de convertirme en un inválido de por vida. Luego subraya que el verdadero terror en la ansiedad no proviene de la muerte en sí misma, sino del hecho de que cada uno de nosotros ocupa en el combate posiciones antagónicas dentro de sí mismo, de que la 'ansiedad es el deseo de lo que uno teme', tal como lo expresó Kierkegaard. Así, es semejante a un 'poder ajeno que se apodera del individuo, y del cual él no puede desasirse'.

Lo que en ese entonces me impresionó sobremanera fue que Kierkegaard escribía exactamente acerca de nuestros sufrimientos. Freud no; escribía en un distinto nivel, formulando los mecanismos psíquicos mediante los cuales surge la ansiedad. Kierkegaard retrataba la experiencia inmediata de los seres humanos en crisis. Se trataba, específicamente, de la crisis de la vida contra la muerte, la cual, para nosotros, pacientes, era absolutamente real; pero escribía acerca de una crisis de las personas que acuden en procura de asistencia médica, o de las que todos experienciamos, aunque de manera atenuada, unas doce veces por día, por más que apartemos de nuestra mente la ineludible perspectiva de la muerte. Freud escribía en un nivel técnico, donde su genio señoreaba; quizá sabía acerca de la ansiedad más que cualquier otro hombre de su época. Kierkegaard, un genio de otro tipo, escribía en un nivel existencial-ontológico: conocía la ansiedad ${ }^{20}$.

Lo curioso es que toda la gran obra de Kierkegaard late bajo el signo psicológico; es desde tal perspectiva que se sentía más cómodo. Los subtítulos de sus dos obras más influyentes y profundas lo acreditan: El concepto de la angustia se presenta por Vigilius Haufniensis como Una sencilla investigación psicológica orientada bacia el problema del pecado original (1844), aunque de sencilla poco tenía y tiene; véase su permanente vigencia. Por su parte, La enfermedad mortal o de la desesperación y el pecado se introduce por su otro alter ego, Anti-Climacus, como Una exposición cristiano-psicológica para edificar y despertar (1849). Además, menos leída, es cierto, se propuso hasta una obra como La repetición signada por Constantin Constantius como Un ensayo de psicología experimental (1843). Por supuesto que Kierkegaard no se tenía por psicólogo. Él solo quería escribir y no será hasta el final de sus días que desde lo escrito pretenderá con El instante (1855) ser más expansivo, beligerante. Aún entonces se reconocerá sólo como escritor ${ }^{21}$;

${ }^{20}$ Rollo May, "El surgimiento de la psicología existencial”, pp. 18-19.

21 "Ser escritor: eso sí que me agrada. Si tuviera que ser sincero, debería decir que he 
pero un escritor, reitero, con un grado de aplicabilidad en materia psicológica allende el ambiente, los temas cristianos a los que con su pluma se dirigió. Es más, la raíz cristiana de toda la psicología contemporánea, del "aquí y ahora", que emerge como principio en las diferentes escuelas integrantes al menos de la "Tercera Fuerza", como se verá en el epígrafe siguiente, bebe en sus textos. Justamente por ello, porque son pocos los psicoterapeutas existencialistas en la actualidad, aunque el principio mencionado resulte más bien común, es que habría optado por expandir el campo, como pretendiera May, más allá de la tendencia; se entiende ahora el término más amplio de recepción para este epígrafe.

Teniendo en cuenta ello, no habrá ya técnica experiencial, humanista, que no tenga en cuenta en mayor o menor medida la propuesta de May, siendo en este punto paradigmáticas la terapia centrada en el cliente de Carl Rogers (1902-1987) y la guestáltica de Fritz Perls (1893-1970).

El primero, en el mismo año 1961, publicará El proceso de convertirse en persona donde, permítaseme la extensa cita, se expresa como sigue:

En este intento de descubrir su auténtico sí mismo, el cliente habitualmente emplea la relación para explorar y examinar los diversos aspectos de su propia experiencia y para reconocer y enfrentar las profundas contradicciones que a menudo descubre. Entonces aprende que en gran medida su conducta y los sentimientos que experimenta son irreales y no se originan en las verdaderas reacciones de su organismo, sino que son solo una fachada, una apariencia tras la cual trata de ocultarse. Descubre que una gran parte de su vida se orienta por lo que él cree que debería ser y no por lo que es en realidad. A menudo advierte que solo existe como respuesta a exigencias ajenas, y que no parece poseer un sí mismo propio; descubre que trata de pensar, sentir y comportarse de la manera en que los demás creen que debe hacerlo.

En relación con este problema, me ha sorprendido comprobar la precisión con que el filósofo dinamarqués Søren Kierkegaard describió, hace más de un siglo, el dilema del individuo, haciendo gala de un perspicaz insight psicológico. Este autor señala que, por lo general la causa de la desesperación reside en no elegir ni desear ser uno mismo y que la forma más profunda de desesperación es la del individuo que ha elegido "ser alguien diferente de sí mismo". Por otro lado, en el extremo opuesto a la desesperación se encuentra el desear ser el sí mismo que uno realmente es; en esta elección radica la responsabilidad más profunda del hombre. Al leer ciertas páginas de Kierkegaard, presiento que debe haber oído manifestaciones similares a las

estado enamorado del producir, pero con una aclaración: a mi modo" (Søren Kierkegaard, El instante, trad. de Andrés Roberto Albertsen, Trotta: Madrid, 2012, p. 19). 
que expresan nuestros clientes embarcados en la exploración y búsqueda de la realidad de su sí mismo: dolorosa y difícil ${ }^{22}$.

Sin considerarse existencialista, Rogers citará en otras dos ocasiones a Kierkegaard extendiendo su terapia "persona a persona” promovida anteriormente, basada en la congruencia del terapeuta o autenticidad, la aceptación positiva incondicional y la comprensión empática hacia el cliente, en torno a una visión del hombre más amplia y capaz.

Pero si hay un terapia, una técnica teórico-práctica donde emerge la figura de Kierkegaard desde sus mismos fundamentos, amén, claro está, de la que siguiera Rollo May -y, hoy, su más conocido discípulo, Irvin D. Yalom-, esa es la Gestalt creada y difundida con enorme éxito por Fritz Perls, Así, esta terapia "consiste en atender a otro ser humano en tal forma que le permita ser lo que realmente es, 'con fundamento en el poder que lo constituye', según la frase de Kierkegaard. De modo que, continuando con la tradición de Kierkegaard, la terapia Gestalt es una terapia existencialista, que se ocupa de los problemas provocados por nuestra aversión a aceptar la responsabilidad de lo que somos y de lo que hacemos"23.

Ahorabien,la Gestalt podrá catalogarsedeprimeras comoexistencialista, humanista, pero es distinta a las demás. Y en esa su especialidad es que no conviene que se integre con la Psicología existencial como ésta se ha caracterizado hasta aquí. En otras palabras, es una Psicología existencialista, pero hay algo más que la hace especial. Constituye una técnica con plena carta de naturaleza y más que singular en sus principios y modos de aplicación.

Efectivamente, la psicología de la forma, que es lo que significa en alemán Gestalt, considera la experiencia personal como una sucesión de relaciones figura-fondo en las que las necesidades específicas del momento emergen respecto al contexto, para después desaparecer, una vez satisfechas, y ser sustituidas por nuevas configuraciones, nuevas necesidades. "Si una necesidad no se satisface y la forma no se completa, se creará un conflicto psíquico. El bienestar y la salud mental se derivan sobre todo del conocimiento por parte del sujeto del continuo proceso de formación, disolución y reformulación de la forma que va asumiendo en cada ocasión su existencia según los contextos en los que se está manifestando y en las

${ }^{22}$ Carl Rogers, El proceso de convertirse en persona. Mi técnica terapéutica, trad. de Liliana R. Wainberg, Barcelona: Paidós Ibérica, 2006, p. 105.

${ }^{23}$ Fritz Perls y Patricia Baumgardner, Terapia Gestalt, trad. de Victorino Pérez, México: Pax, 2003, p. 19. 
diferentes configuraciones que van asumiendo los mismos"24; como escribe Perls "la calidad más importante e interesante de una forma es su dinámica, la imperiosa necesidad que posee una forma y que la lleva a cerrarse y a completarse. Todos los días experimentamos esta dinámica. A veces el mejor nombre que se le puede dar a una forma incompleta es, simplemente, situación inconclusa" 25 . Y así, los asuntos que no han sido experimentados de forma completa vuelven una y otra vez a la vida presente, interfiriendo el contacto con uno mismo y con los demás. Surge aquí el concepto de resistencia que resulta cualquier obstáculo puesto por el individuo impediente del cumplimiento de sus necesidades psíquicas. Frente al psicoanálisis ${ }^{26}$, la Gestalt no busca vencer las resistencias sino hacer que se tome conciencia de ellas empleándose de forma adaptada en función del momento y la situación ${ }^{27}$.

\section{Especial consideración del "aqui y abora" kierkegaardiano en la psicote- rapéutica actual}

Precisamente en la terapia gestáltica, "cualesquiera que sean los problemas, las fantasías que traiga en su cabeza, a medida que se acerca, cualquiera que sea su apariencia, el paciente viene en busca de tratamiento porque siente que está en una crisis existencial, es decir, siente que las necesidades psicológicas con las que se ha identificado y son tan vitales para él como su aliento, no están siendo atendidas en su modo actuar de vida. Las necesidades psicológicas que asumen esta importancia de vida o muerte son tantas y tan variadas como lo son los pacientes. Para uno, el mantenerse a la altura de los vecinos y el superarlos, en lo posible, es una necesidad dominante. Para otro, el tener la devoción exclusiva de su esposa, marido o amante. Si tal persona no logra su cometido, o si habiéndolo logrado lo llega a perder, está en una crisis existencial. Para un neurótico el 'autocontrol' es una necesidad existencial; para otro, la 'autoexpresión'. [Pues bien] cualesquiera que sean las necesidades existenciales, el hecho de venir a la terapia es la admisión del paciente de que no están siendo satisfechas

${ }^{24}$ Umberto Galimberti, "Psicología de la forma", en Diccionario de Psicología, trad. de María Elena G. de Quevedo, México: Siglo XXI, 2002, p. 73.

${ }^{25}$ Ibíd.

${ }^{26}$ Fritz Perls, El enfoque guestáltico y testimonios de terapia, trad. de Francisco Huneeus, Santiago de Chile: Cuatro vientos, 1976, p. 120.

${ }^{27}$ Ibíd., p. 23. 
[es esa decisión previa a la que aludía May], consulta al terapeuta porque espera encontrar en éste el apoyo ambiental que suplementará a sus propios medios inadecuados de apoyo"28.

¿Y desde qué perspectiva debe recibirlo, entonces, el terapeuta? Pues desde el "aquí y ahora", aspecto éste que se cifra en la experiencia de vivir el presente, de obviar la excavación en el pasado, represiones, conflictos edípicos y escenas primarias. En esta "situación de vida", el paciente aprenderá por sí mismo a integrar sus pensamientos, sentimientos, acciones, y no únicamente en la sala de consulta sino en el trascurso de su vida cotidiana, apostilla Perls ${ }^{29}$.

Pero el "aquí y ahora", la "tendencia al vivir existencial", como la denominara Rogers ${ }^{30}$, no es patrimonio de escuela alguna, no; no al menos

${ }^{28}$ Ibíd., p. 53.

${ }^{29}$ Ibíd., p. 29.

${ }^{30}$ Que desarrolla así: "a mi juicio, una segunda característica del proceso de una vida plena consiste en una mayor tendencia a vivir íntegramente cada momento. Este pensamiento puede ser mal interpretado con suma facilidad y quizá yo tampoco lo comprenda con claridad. Intentaré explicar lo que esto significa.

Pienso que todo momento es nuevo para la persona que se abre a su nueva experiencia de manera plena y sin defensa alguna. Nunca antes habrá existido la configuración compleja de estímulos internos y externos que existe en este momento. Por consiguiente, esta persona deberá reconocer que 'lo que yo sea y haga en el momento siguiente dependerá de ese momento, y ni yo ni los demás podemos predecirlo de antemano'. Con frecuencia vemos que los clientes expresan este tipo de sentimientos.

Una manera de expresar la fluidez de este vivir existencial es decir que el sí mismo y la personalidad emergen de la experiencia que ahora no debe ser distorsionada o moldeada para ajustarse a determinada estructura preconcebida del sí mismo. Esto significa que el individuo se convierte a la vez en observador y partícipe del proceso de la experiencia organísmica, y no se ve obligado a ejercer control sobre él.

Este vivir en el momento no implica una ausencia de rigidez, de organización estricta y de imposición de la estructura sobre la experiencia. Significa, en cambio, un máximo de adaptabilidad, un descubrimiento de la estructura en la experiencia, una organización fluida y cambiante del sí mismo y de la personalidad.

Pienso que esta tendencia al vivir existencial se observa con mucha claridad en las personas que se han embarcado en el proceso de la vida plena; hasta se podría decir que ésta es su característica esencial. Esta tendencia implica descubrir la estructura de la experiencia en el proceso de vivirla. Por otra parte, la mayoría de nosotros incorporamos a nuestra experiencia una estructura y evaluación preconcebidas que nunca abandonamos por completo, y mediante las cuales distorsionamos y simplificamos la experiencia, cuya fluidez dificulta su introducción en nuestros casilleros, cuidadosamente preparados para alojarlo. Una de las cualidades principales de los clientes que veo aproximarse a la vida plena y madura consiste en que abren su espíritu a lo que está sucediendo abora y descubren la estructura de ese proceso, cualquiera que sea su naturaleza" (Carl Rogers, El proceso de 
dentro de la corriente humanista que correlaciona con toda la Psicología de nuestro tiempo. Y ello es tan lógico como que el pasado no puede imponerse sobre nuestra voluntad, que no estamos predeterminados por él, en tanto que el futuro, por su parte, desde tal perspectiva no existe en puridad, solo es un concepto, un propósito a lo más, pero que no debe interferir con el presente y sus necesidades. Sin la superación de éstas no habría propósito futuro que valga. Solo así se puede entender, creo yo, una de las citas más frecuentes de las atribuidas a Rollo May, aquella por la cual "la depresión es la incapacidad de construirse un futuro”. Efectivamente, a él corresponde, pero está incompleta, por cuanto en la obra en la que se incluye, Existence, May dice exactamente lo siguiente: "la ansiedad severa y la depresión borran el tiempo, anulan el futuro"; para añadir que "también puede ser, como propone Minkowski, que la desorientación del paciente en relación con el tiempo, su incapacidad para 'poseer' su futuro provoque su ansiedad y depresión" 31 . En todo caso, Yalom advierte sobre la sobrecarga que para la voluntad del paciente puede implicar el tomar decisiones en el presente para el futuro. Recuerda exactamente cómo la mayor parte de los terapeutas existenciales -y por extensión humanistas- "se centran menos en el pasado que otras escuelas; por el contrario, hacen mucho más hincapié en el tiempo futuro, en las decisiones por tomar y en las metas que ante sí tiene el paciente. Cuando estos terapeutas se enfrentan con la culpa, éste no se refiere a las elecciones incorrectas, sino a la negativa a decidirse. Es extraordinariamente difícil absolver a un paciente por la culpa de su pasado, en presencia de una conducta que continúa provocando culpas. Uno tiene que aprender, ante todo, a perdonarse a sí mismo por el presente y el futuro. Mientras uno continúe en el presente teniendo hacia su propio yo la misma actitud que tenía en el pasado, no podrá perdonarse por éste. Pero, aun trabajando en el pasado, es importante que el individuo no asuma una responsabilidad desproporcionada" 32 . Esta sería su teoría, pero en su libro de tono más práctico El don de la terapia se muestra entusiasta con el uso del "aquí y ahora" en cada sesión por dos razones claves: de un lado, por la importancia de las relaciones interpersonales; de otro, por la condición del espacio terapéutico como microcosmos social ${ }^{33}$.

convertirse en persona. Mi técnica terapéutica, pp. 169-170).

${ }^{31}$ Rollo May, "Contribuciones de la psicoterapia existencial”, p. 95.

${ }^{32}$ Irvin, D. Yalom, Psicoterapia existencial, p. 420.

33 Irvin D. Yalom, El don de la terapia. Carta abierta a una nueva generación de psicoterapeutas y a sus pacientes, trad. de Jorge Salvetti, Buenos Aires: Emecé, 2004, p. 65. 
Sea como fuere, se limite el "aquí y ahora" a la mera sesión como al presente in genere en la vida del paciente como enfatiza la Gestalt, no cabe duda de que la matriz del subjetivismo kierkegaardiano se muestra a su través claramente visible. Ya no por los temas a tratar en la terapia, y que antes se apuntaran, todos pertinentes con su obra, sino por el enfoque, el eje temporal como factor de relevante consideración con que se aplica.

Antes de entrar en la que él llamaba la "preocupación de atormentarse" por el día de mañana, conviene, no obstante, brindar, ofrecer el concepto preciso que Kierkegaard mantenía sobre la Psicología: en su introducción a El concepto de la angustia ${ }^{34}$ luego de declarar -premonitoriamente- que el objeto de la Psicología tenía "que ser algo estable, que permanezca en una quietud algo movida, pero que no sea una pura inquietud, algo que no cesa de reproducirse y reprimirse" 35 , hacía suya su calificación como "doctrina del espíritu subjetivo"36. ¿Y qué era para él esto exactamente? Ello nos lo dirá, en justa complementación, en las primeras páginas de La enfermedad mortal. El espíritu subjetivo sería el yo, la conciencia presente de ser, uno mismo, si se quiere, pero mucho más exactamente: "el yo es una relación que se relaciona consigo misma, o dicho de otra manera: es lo que en la relación hace que ésta se relacione consigo misma. El yo no es la relación, sino el hecho de que la relación se relacione consigo misma. El hombre es una síntesis de infinitud y finitud, de lo temporal y eterno, de libertad y necesidad, en una palabra, es una síntesis. Y una síntesis es la relación entre dos términos. El hombre, considerado de esta manera, no es todavía un yo”. Para de inmediato añadir que "en una relación entre dos términos, la relación es lo tercero como unidad negativa y los dos se relacionan con la relación y en relación con la misma; de este modo, y en lo que atañe a la definición de 'alma', la relación entre alma y el cuerpo es una simple relación. Por el contrario, si la relación se relaciona consigo misma, entonces esta relación es lo tercero positivo, y esto es cabalmente el yo" 37 .

${ }^{34}$ Introducción que se presenta así: "En qué sentido el tema de la investigación [el pecado original] sea un problema que interese a la Psicología, y después de haber sido un problema interesante para ésta, en qué sentido se refiera cabalmente a la Dogmática" (Søren Kierkegaard, El concepto de la angustia, trad. de Demetrio Gutiérrez Rivero, Alianza: Madrid, 2016 p. 45).

${ }^{35}$ Ibíd., p. 67.

${ }^{36}$ Ibíd., p. 71.

37 Søren Kierkegaard, La enfermedad mortal, trad. de Demetrio Gutiérrez Rivero, Trotta: Madrid, 2008, p. 33. 
Esta perspectiva calaría entre los psicólogos décadas después, con ilustrativa omisión en Freud en su cita, más allá de la óptica 'cristiana', 'espiritual', de sus obras; y es que el protagonista sería el hombre encerrado en su angustia y desesperanza, asuntos que trascienden al hombre, sea o no cristiano. Aquí radica la permanente vigencia de Kierkegaard y su necesidad de conocimiento por el psicólogo, lamentablemente tan poco atendida ${ }^{38}$.

Ahora sí estamos en disposición de comprender los demás textos de Kierkegaard, y dándole la vuelta al discurso no renunciar a admitir que existe una profunda raíz cristiana por su medio en la psicología contemporánea que se base en el "aquí y ahora", que renuncie a la postre al determinismo psicológico. En tal espejo se refleja el pasaje evangélico sobre la solicitud de lo temporal, acerca del cual Kierkegaard escribirá sus trece magníficos discursos religiosos agrupados bajo el acápite Los lirios del campo y las aves del cielo (1848-1849), que dice así:

Por esto os digo: no estéis angustiados por vuestra existencia, pensando qué vais a comer o beber, ni por el cuerpo, pensando con qué os vais a vestir. ¿No vale más la vida que el alimento, y el cuerpo que el vestido? Mirad a las aves del cielo, que no siembran, ni siegan, ni almacenan y, sin embargo, vuestro Padre celestial las alimenta. ¿No valéis vosotros más que ellas? ¿Quién de vosotros, a fuerza de agobiarse, podrá añadir un solo codo a su estatura? ¿Por qué os agobiáis por el vestido? Fijaos cómo crecen los lirios del campo: ni trabajan ni hilan. Y os digo que ni Salomón, en todo su fasto, estaba vestido como uno de ellos. Pues, si a la hierba, que hoy está en el campo y mañana se quema en el horno, Dios la viste así, ¿no hará mucho más por vosotros, gente de poca fe? No andéis agobiados, pensando qué vais a comer, o qué vais a beber, o con qué os vais a vestir. Los gentiles se afanan por esas cosas. Ya sabe vuestro Padre del cielo que tenéis necesidad de todo eso. Sobre todo, buscad el Reino de Dios y su Justicia; lo demás se os dará por añadidura. Por tanto, no os angustiéis por el día de mañana, porque el día de mañana se cuidará de sí: bástale a cada día su trabajo (Mt 6: 25-34).

${ }^{38} \mathrm{Y}$ es una pena sí por cuanto, como se ha dicho, "las aportaciones de Kierkegaard pueden enriquecer la psicoterapia y enseñarnos (a pacientes y terapeutas) a encontrar una solución a la angustia, a salir del error y aproximarnos a la verdad, a dar más que recibir, a comprender y auto-comprendernos, a entender la libertad como interdependencia personal, a ayudarnos a perdonar y perdonarnos, a disolver la desesperación en una confiada esperanza, a trabajar mejor con la ironía socrática, a magnificar el respeto al otro y a sí mismo, en definitiva a llevar una existencia más auténtica a fin de que lleguemos a ser la mejor persona posible" (Aquilino Polaino-Lorente, "Kierkegaard y los psicoterapeutas", en La vocación y la formación del psicólogo clínico, ed. por Aquilino Polaino-Lorente y Gema Pérez Rojo, Bilbao: Desclée de Brouwer, 2014, p. 115). 
Con motivo de estos versículos, vuelve Kierkegaard sobre la angustia, sobre el tormento de pensar en el mañana en detrimento del presente, pero con mayor claridad que en su obra de 1844. Naturalmente que el pájaro, enfatizará, "no tiene ninguna preocupación por el día de mañana. Y precisamente esta preocupación es el atormentarse, y por eso, el pájaro está sin la preocupación de atormentarse. ¿Qué es el atormentarse? Es un afán que no tiene el día de hoy, que ya tiene bastante con su propio afán. ¿Qué es el atormentarse? Forzar en uno mismo ese afán"39.

Para cuidarnos de no caer en lo que él llama "enorme diferencia", la de prestarnos al día de mañana, la de caer en la trampa del futuro, no debemos fijarnos en la superficialidad del sustento, el qué comeremos, cómo vestiremos. $\mathrm{Y}$ es que en "el fondo todas las preocupaciones terrenas y mundanas lo son para el día siguiente. Todas esas preocupaciones son cabalmente posibles en cuanto al hombre, que es una síntesis de lo temporal y lo eterno [anticipa aquí la misma idea que en La enfermedad mortal], llegó a ser un 'yo'; mas en cuanto llegó a ser un 'yo', empezó también a existir el día siguiente para él" ${ }^{40}$, tomó conciencia del futuro, empezó su soberbia batalla con el futuro y, por ende, con su finitud.

Para el hombre desasido, para el cristiano, el día de mañana, con todas sus preocupaciones no puede ni debe existir. Usando el símil que utiliza Kierkegaard, es como aquel que en un bote rema de espaldas a la orilla a la que se va acercando, pero sin darse nunca vuelta hacia atrás pues con ello interrumpiría justamente su devenir y hasta su trayectoria. El remador cada vez estará más cerca de la meta, que es la eternidad, a cada remada, a cada día que toma como suyo sin preocuparse por mirar a un atrás que es en realidad un delante; no le importa lo que terceros puedan contemplar ni decir, vive el presente, no se atormenta. En cambio, el que rema de cara sí lo hará, solo piensa en llegar a una meta durante un banal camino lleno de preocupaciones, de insolencia, de impotencia. "Porque ¡cuán raros son los hombres realmente contemporáneos consigo mismos! La mayoría están a cientos de miles de kilómetros por delante de sí mismos, gustosamente precipitados en los sentimientos, la fantasía, los designios, las resoluciones, los deseos y ansias, y espectacularmente en el encantamiento iluso del teatro: o están varias generaciones adelantados a sí mismos. Mas el creyente -el presente- es contemporáneo consigo mismo en el sentido más

\footnotetext{
${ }^{39}$ Søren, Kierkegaard, Los lirios del campo y las aves del cielo. Treces discursos religiosos, trad. de Demetrio Gutiérrez Rivero, Guadarrama: Madrid, 1963, p. 191.

${ }^{40}$ Ibíd., p. 191. 
profundo de la palabra. Y esto de ser, con la ayuda de lo eterno, plenamente contemporáneo consigo mismo en el día de hoy, es también lo que más forma y perfecciona la vida humana, es el beneficio de la eternidad. Jamás ha existido ningún acontecimiento contemporáneo, ni ninguna celebridad contemporánea, tan grandes como la eternidad. Y esta contemporaneidad hoy es cabalmente la tarea: su solución es la fe" ${ }^{41}$.

Por el contrario, para el gentil, o mejor, el hombre corriente, el impenitente, el intrascendente, "lo que sea el día de hoy, si alegre o triste, dichoso o desgraciado, propiamente no hace al caso porque es incapaz tanto de gozarlo como de emplearlo debidamente, ya que no puede echar de la imaginación la misteriosa escritura que destaca en sus paredes: ‘ Mañana!’”2, que es la misma angustia, por ello cuanto más dichoso es el pagano más le invade la angustia, "porque probablemente la adversidad y la desgracia contribuyen en parte a apagar el fuego de su preocupación terrena. Ya que la terrena preocupación da a luz, engendrándola, a la angustia, y ésta, a su vez, alimentándola, da a luz a la preocupación" ${ }^{3}$.

Dado todo ello, el cierre no puede ser otro: en la búsqueda del significado de la vida, tarea propia de toda la corriente existencialista de la psicología, el componente espiritual, trascendente no sólo será objeto del tratamiento, sino coadyuvante para el progreso del paciente, sea éste cristiano o no. Porque más allá de cuerpo y mente, todavía queda el espíritu, y ésta es una dimensión insoslayable del hombre para con su integralidad.

\section{Bibliografía}

Kierkegaard, Søren, Los lirios del campo y las aves del cielo. Treces discursos religiosos, trad. de Demetrio Gutiérrez Rivero, Guadarrama: Madrid, 1963.

L L enfermedad mortal, trad. de Demetrio Gutiérrez Rivero, Trotta: Madrid, 2008.

—_El instante, trad. de Andrés Roberto Albertsen, Trotta: Madrid, 2012.

- El concepto de la angustia, trad. de Demetrio Gutiérrez Rivero, Alianza: Madrid, 2016.

Ferrater Mora, José, Diccionario de Filosofía, Buenos Aires: Editorial Sudamericana, 1964.

\footnotetext{
${ }^{41}$ Ibíd., pp. 196-197.

${ }^{42}$ Ibíd., p. 201

${ }^{43}$ Ibíd., p. 202.
} 
Galimberti, Umberto Diccionario de Psicología, trad. de María Elena G. de Quevedo, México: Siglo XXI, 2002.

May, Rollo, Angel, Ernest y Ellenberger, Henri, F., Existence: A New Dimension in Psychiatry and Psychology, Nueva York: Basic Books, 1958.

— Gordon. W., Feifel, Herman et. al., Existencial Psychology, Nueva York: Random House, 1961.

"El surgimiento de la psicología existencial", en Psicología existencial, ed. por May, Rollo, Allport, Gordon. W., Feifel, Herman et. al., trad. de Marcelo Cherbi, Buenos Aires: Paidós, 1963, pp. 9-58.

_- "Orígenes y significado del movimiento existencial en psicología”, en Existencia: nueva dimensión en psiquiatría y psicología, ed. por May, Rollo, Angel, Ernest y Ellenberger, Henri, F., trad. de Cecilio Sánchez Gil, Gredos: Madrid, 1977, pp. 19-57.

__Contribuciones dela psicoterapia existencial”, en Existencia:nueva dimensión en psiquiatría y psicología, ed. por May, Rollo, Angel, Ernest y Ellenberger, Henri, F., trad. de Cecilio Sánchez Gil, Gredos: Madrid, 1977, pp. 58-122.

L Libertad y destino en psicoterapia, trad. de Luis Martínez Gómez, Bilbao: Desclée de Brouwer, 1988.

Millán, Rafael, Las enfermedades mentales no existen...son los padres, Madrid: Manuscritos, 2017.

Perls, Fritz, El enfoque guestáltico y testimonios de terapia, trad. de Francisco Huneeus, Santiago de Chile: Cuatro vientos, 1976.

— y Baumgardner, Patricia, Terapia Gestalt, traducción de Victorino Pérez, Mexico: Pax, 2003.

Polaino-Lorente, Aquilino, "Kierkegaard y los psicoterapeutas", en La vocación y la formación del psicólogo clínico, ed. por Polaino-Lorente, Aquilino y Pérez Rojo, Gema, Bilbao: Desclée de Brouwer, 2014, pp. 87-115.

Rogers, Carl, El proceso de convertirse en persona. Mi técnica terapéutica, trad. de Liliana R. Wainberg, Barcelona: Paidós Ibérica, 2006.

Sartre, Jean-Paul, El existencialismo es un humanismo, [no indica trad.], Madrid: Edhasa, 2009.

Szasz, Thomas, The Myth of Mental Illness: Foundations of a Theory of Personal Conduct, Nueva York: Hoeber \& Row, 1961.

Tortosa Gil, Francisco, Una bistoria de la psicología moderna, Madrid: McGrawHill, 1998.

Yalom, Irvin D., Psicoterapia existencial, trad. de Diorki, Barcelona: Herder, 1984. _ El don de la terapia. Carta abierta a una nueva generación de psicoterapeutas y a sus pacientes, trad. de Jorge Salvetti, Buenos Aires: Emecé, 2004. 